\title{
Carbon budgets from mariculture ponds without a food supply
}

\author{
Yan Chen ${ }^{1,2}$, Shuanglin Dong ${ }^{2, *}$, Yucen $\mathrm{Bai}^{3}{ }^{3}$, Shaogang Xu${ }^{1}$, Xiaofei Yang ${ }^{1}$, Zhe Pan ${ }^{2}$ \\ ${ }^{1}$ Beijing Fisheries Research Institute, Beijing 100068, China \\ ${ }^{2}$ Key Laboratory of Mariculture, Ministry of Education of China. Ocean University of China, Qingdao 266003, PR China \\ ${ }^{3}$ China Rural Technology Development Center, 54 Sanlihe Road, Beijing 100045, PR China
}

\begin{abstract}
To estimate the carbon source-sink function of mariculture ponds without a food supply, we analyzed carbon budgets and gaseous carbon fluxes in shrimp Marsupenaeus japonicus-sea cucumber Apostichopus japonicus polyculture seawater ponds (PSPs) without feeding. Over a 1 yr cycle, the total organic carbon outflow accounted for $78.6 \%$ of the inflow organic carbon in PSPs. Approximately $1558.1 \mathrm{~kg} \mathrm{ha}^{-1}$ of organic carbon accumulated in PSPs, and the ratio of gaseous carbon exchange to carbon burial ranged from 0.73 to 1.45. The PSPs acted as a purification system where organic carbon is eliminated from the inflow water, and carbon retention in the sediment of such systems could offset their carbon emissions into the atmosphere.
\end{abstract}

KEY WORDS: Mariculture ponds $\cdot$ No-feeding $\cdot$ Methane $\cdot$ Carbon dioxide $\cdot$ Carbon budgets

\section{INTRODUCTION}

The organic carbon pool can be used to characterize the function and structure of aquatic systems. Aquaculture ponds are semi-artificial ecosystems; thus, the management of these ponds, including daily feeding and water exchange, could have an effect on their organic carbon budget. Organic carbon budgets can be used to quantify the potential impact of specific artificial management strategies on pond systems and indicate the water quality of these ponds. This approach has been previously used for fish (Liu et al. 2002, Sahu et al. 2015, Guo et al. 2017), shrimp (Hopkins et al. 1993) and sea cucumber aquaculture ponds (Li et al. 2015).

The supply of feed influences the organic carbon content and, therefore, the organic carbon budget of aquaculture ponds. For example, in integrated shrimp mariculture ponds with a feed supply, the total input of organic carbon has been shown to be $55 \%$ more than the output (Liu et al. 2002). Of the organic carbon input, less than $10 \%$ is converted into shrimp production, and $35 \%$ is retained in the cul-

${ }^{*}$ Corresponding author: dongsl@ouc.edu.cn ture system (Liu et al. 2002). Integrated sea cucumber aquaculture systems without a feed supply can eliminate $7.3 \%$ of the organic carbon input (Li et al. 2015); therefore, such integrated systems not only result in aquacultural products, but also act as an organic matter purification system for the surrounding environment.

Both carbon exchange across the water-air interface and carbon sequestration have important roles in carbon circulation in aquatic ecosystems. For example, oceans are likely to act as a sink for $80-95 \%$ of the anthropogenic $\mathrm{CO}_{2}$ emissions over a multimillennial time scale (Archer et al. 2000). Furthermore, oceans emit an estimated 10.9-17.8 $\mathrm{Tg} \mathrm{CH}_{4}$ annually across the water-air interface (Ortiz-Llorente \& Alvarez-Cobelas 2012), whereas they store approximately $3.9 \times 10^{16} \mathrm{~kg}$ of carbon, which corresponds to $93 \%$ of the total carbon in the global ecosystem (Rödenbeck et al. 2013). Although inland aquatic ecosystems also contribute gaseous carbon, including $\mathrm{CO}_{2}$ and $\mathrm{CH}_{4}$, to the atmosphere across the water-air interface (Xing et al. 2005, Zhang et al. 2008, Chen et al. 2015), they also have significant car-

() The authors 2018. Open Access under Creative Commons by Attribution Licence. Use, distribution and reproduction are unrestricted. Authors and original publication must be credited. 
bon sequestration potential (Yang et al. 2008, Franzén et al. 2012). Total carbon sinks in lakes, including inorganic carbon and organic carbon, were reported to be $7.7 \times 10^{10} \mathrm{~kg} \mathrm{yr}^{-1}$, of which the sink from the atmosphere accounts for $5.32 \times 10^{10} \mathrm{~kg} \mathrm{yr}^{-1}$ (Downing et al. 1993). Freshwater aquaculture ponds in temperate monsoon climate regions are estimated to contribute approximately $2.98 \times 10^{9} \mathrm{~kg} \mathrm{yr}^{-1} \mathrm{CO}_{2}$ to the atmosphere (Chen et al. 2015). Aquaculture ponds sequester an estimated $1.66 \times 10^{10} \mathrm{~kg} \mathrm{yr}^{-1}$ of carbon worldwide, representing approximately $0.21 \%$ of annual global carbon emissions (Boyd et al. 2010), in the form of organic carbon from uneaten feed, organic fertilizers, dead plankton and excreta. So far, no detailed studies have considered the carbon source-sink functions of specific aquaculture ponds in terms of both the water-air interface and carbon sequestration.

To estimate the carbon source-sink function of mariculture ponds without a food supply, we constructed a comprehensive carbon budget, including gaseous carbon exchange across the water-air interface using floating static chamber technology, in 3 shrimp and sea cucumber polyculture seawater ponds (PSPs) without a food supply. In addition, we also calculated the organic carbon concentration across the inflow water, outflow water and the water-sediment interface to access the environmental effect of the no-feeding mariculture system.

\section{MATERIALS AND METHODS}

\section{Experimental ponds}

The experiments were carried out on a mariculture farm in Qingdao $\left(36^{\circ} 18^{\prime} \mathrm{N}, 120^{\circ} 00^{\prime} \mathrm{E}\right)$, Shandong Province, PR China, which has a typical temperate monsoonal climate with a mean annual temperature of $12.3^{\circ} \mathrm{C}$. The studies were conducted in 3 rectangular sea cucumber Apostichopus japonicus PSPs (160.0 m length $\times 70.3 \pm 7.8 \mathrm{~m}$ width $\times 3.0 \pm 0.1 \mathrm{~m}$ depth) from 30 March 2014 to 26 March 2015. The ponds used in the experiments were selected at random from across the farm. The study period encompassed 2 shrimp farming seasons: spring (from 30 March to 20 July) and autumn (from 3 August to 22 November). PSPs were stocked with juvenile sea cucumbers on 7 April 2014 and cultured for 1 yr. The seawater in the ponds was routinely exchanged during each spring tide. No supplemental feed was provided to these ponds during the study period. Table 1 details the stocking densities of shrimp and sea cucumber in PSPs.
Table 1. Stocking and water quality $\left(\mathrm{mg} \mathrm{l}^{-1}\right)$ of polyculture seawater ponds without a food supply during farming seasons. Spring: first shrimp culture season from 30 Mar to 20 Jul; autumn: second shrimp culture season from 3 Aug to 22 Nov; winter: season after shrimp harvest from 23 Nov to 26 Mar. SH: shrimp Marsupenaeus japonicas; SC: sea cucumber Apostichopus japonicas; TN: total nitrogen; TP: total phosphorus

\begin{tabular}{|lccccc|}
\hline Season & $\begin{array}{c}\text { Stocking } \\
\text { species }\end{array}$ & $\begin{array}{c}\text { Stocking density } \\
\left(\text { (ind. }^{-2}\right)\end{array}$ & TN & TP & $\begin{array}{c}\text { Chl a } \\
\left(\mu \mathrm{g} \mathrm{l}^{-1}\right)\end{array}$ \\
\hline Spring & SH & 6.01 & 2.63 & 0.20 & 3.17 \\
& SC & 11.5 & & & \\
Autumn & SH & 1.8 & 3.03 & 0.17 & 4.78 \\
& SC & - & & & \\
Winter & SC & - & 3.41 & 0.19 & 1.54 \\
\hline
\end{tabular}

\section{Water sample collection and analysis}

During the study period, 9 water samples (samples of surface, middle and bottom water layers at 3 different sites) from each pond were collected twice a month. During each spring tide, inflow or outflow water samples were collected repeatedly and pooled as one sample. The amount of inflow water and outflow water was measured using a flow velocity meter (LS1206B, Haosheng Industry and Trade). The samples were stored in clean plastic bottles (2 l) and transported to the laboratory immediately after sampling. The total nitrogen (TN) content of the water was analyzed using the potassium peroxydisulfate oxidation method developed by Grasshoff et al. (2007), and total phosphorus (TP) was analyzed according to Murphy \& Riley (1962). Chlorophyll a (chl a) was extracted with acetone in the dark for $24 \mathrm{~h}$ following filtration of the water samples through GF/F glass microfiber filters; chl a concentrations were analyzed according to the method of the National Standardization Management Council (2007). Water samples for dissolved organic carbon (DOC) were analyzed using a multi2100s TOC analyzer (Analytik Jena) after being filtered through pre-combusted Whatman GF/F filters. Particulate organic carbon (POC) on each filter was determined using a PE-24 CHN analyzer (Heraecus) after acidizing for $4 \mathrm{~h}$ with $1 \mathrm{~N} \mathrm{HCl}$ to remove the carbonate (Holmer et al. 2007). POC plus DOC equals the total organic carbon (TOC) in the water samples.

\section{Measurement of net primary production}

Net primary production (NPP) was measured using the light-dark bottle $(300 \mathrm{ml})$ method simultaneously 
with the gas sample collection (Eaton et al. 1995). Measurements were made by recording the change in $\mathrm{O}_{2}$ concentration over $24 \mathrm{~h}$ at 3 different water depths in each tank (surface, middle and bottom). Once the samples had been collected as described above, 3 light and 2 dark bottles were suspended at each water depth to determine the initial oxygen concentration in each pond. Oxygen concentrations were measured using the Winkler method. Organic carbon resulting from NPP was determined by 0.375 of the cumulative mean values of the differences between the light bottles and initial oxygen concentrations at each depth. From the beginning of July 2014 to the end of September 2014, the PSPs were affected by the growth of the macroalga Enteromorpha sp. In the PSPs, macroalgae from $1 \mathrm{~m}^{2}(1 \times 1 \mathrm{~m})$ of the bottom at 5 sampling points of each tank were collected and weighed to determine the wet biomass. Additionally, $1.0 \mathrm{~g}$ of Enteromorpha was put into each of 2 light and 2 dark bottles at each sampling depth in each pond (Thomas 1988). Further, 2 light and 2 dark bottles without macroalgae were suspended at each depth as controls to measure the NPP by phytoplankton in the PSPs. The difference in NPP between the bottles with and without macroalgae represented the NPP potential of the macroalgae. NPP in the water column was evaluated as: NPP $=$ NPP potential of macroalgae $\times$ wet biomass + NPP of phytoplankton (Zhao et al. 2002, Chen et al. 2016).

\section{Collection and analysis of animals and sediment samples}

The survival and average weight of each sea cucumber were estimated using periodic sampling at 5 sampling quadrats $(2 \times 2 \mathrm{~m})$ in each PSP. All the sea cucumbers in each quadrat were collected, weighed and counted, and then returned to the ponds. The sediment $(5 \mathrm{~cm})$ samples were collected using a cylindrical metal corer ( $5 \mathrm{~cm}$ in diameter) at the same site for each sample. Experimental shrimp, sea cucumbers and sediment samples were dried at $60^{\circ} \mathrm{C}$ to a constant weight, then smashed and sieved using a sample sifter. The organic carbon content of each of these samples was determined using a PE-24 CHN analyzer (Heraecus) after acidifying the samples for $4 \mathrm{~h}$ with $1 \mathrm{~N} \mathrm{HCL}$ to remove any inorganic carbon (Holmer et al. 2007).

\section{Gas sample collection and analysis}

$\mathrm{CO}_{2}$ and $\mathrm{CH}_{4}$ at the air-water interface were measured using the floating static chamber method (Xing et al. 2005, Chen et al. 2015). The chamber $(50 \mathrm{~cm}$ in height and $30 \mathrm{~cm}$ in diameter) was made from Plexiglas. A small vertical vent stopped with a silicone septum on the top was used for sampling. Each chamber was equipped with a circulating fan $(4.5 \mathrm{~V})$ to ensure complete gas mixing and wrapped with a layer of aluminum foil to minimize air temperature changes inside the chamber during the sampling period (Chen et al. 2016). Three replicate chambers were placed in each pond. Prior to sampling, the syringe was pumped several times to mix the air inside the chamber. The samplings were taken between 09:00 and 11:00 $\mathrm{h}$ local time at roughly 1- or 2 -wk intervals. Four individual gas samples were collected with a syringe at $0,10,20$ and 30 min after chamber closure, injected into evacuated sample bags and transported to the laboratory in a coolbox. Gas samples were analyzed as quickly as possible with a GC-2010 plus Gas Chromatograph (Shimadzu) connected to an MGS-4 gas sampler and MTN-1 methanizer. The gas samples were injected into the MGS-4 gas sampler and separated from column SS-2 $\mathrm{m} \times 2 \mathrm{~mm}$ at $40^{\circ} \mathrm{C}$ packed with TDX (60-80 mesh). The separated $\mathrm{CO}_{2}$ was converted into $\mathrm{CH}_{4}$ in the MTN-1 methanizer by nickel catalyst at $375^{\circ} \mathrm{C}$, and the $\mathrm{CH}_{4}$ concentrations were detected by the flame ionization detector at $100^{\circ} \mathrm{C}$. The carrier gas

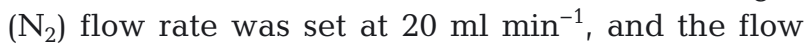
rate of flame gases $\left(\mathrm{H}_{2}\right.$ and compressed air) were 18 and $30 \mathrm{ml} \mathrm{min}^{-1}$, respectively. Standard gases were measured every 4 gas samples in order to determine the sample concentrations and check the errors. The $\mathrm{CO}_{2}$ and $\mathrm{CH}_{4}$ fluxes were calculated from the linear changes in time inside the chamber.

\section{Data analysis}

Data were analyzed using the statistical software SPSS version 18.0. Kolmogorov-Smirnov and Levene's tests were used to test the assumptions of a normal distribution and homogeneity of variance of the data, respectively. Differences in organic carbon between inflow and outflow water were analyzed using paired-sample $t$-tests.

\section{RESULTS}

\section{Organic carbon content of inflow and outflow water}

During the spring farming season, inflow POC, DOC and TOC ranged from 1.79 to $4.22 \mathrm{mg} \mathrm{l}^{-1}, 3.24$ 

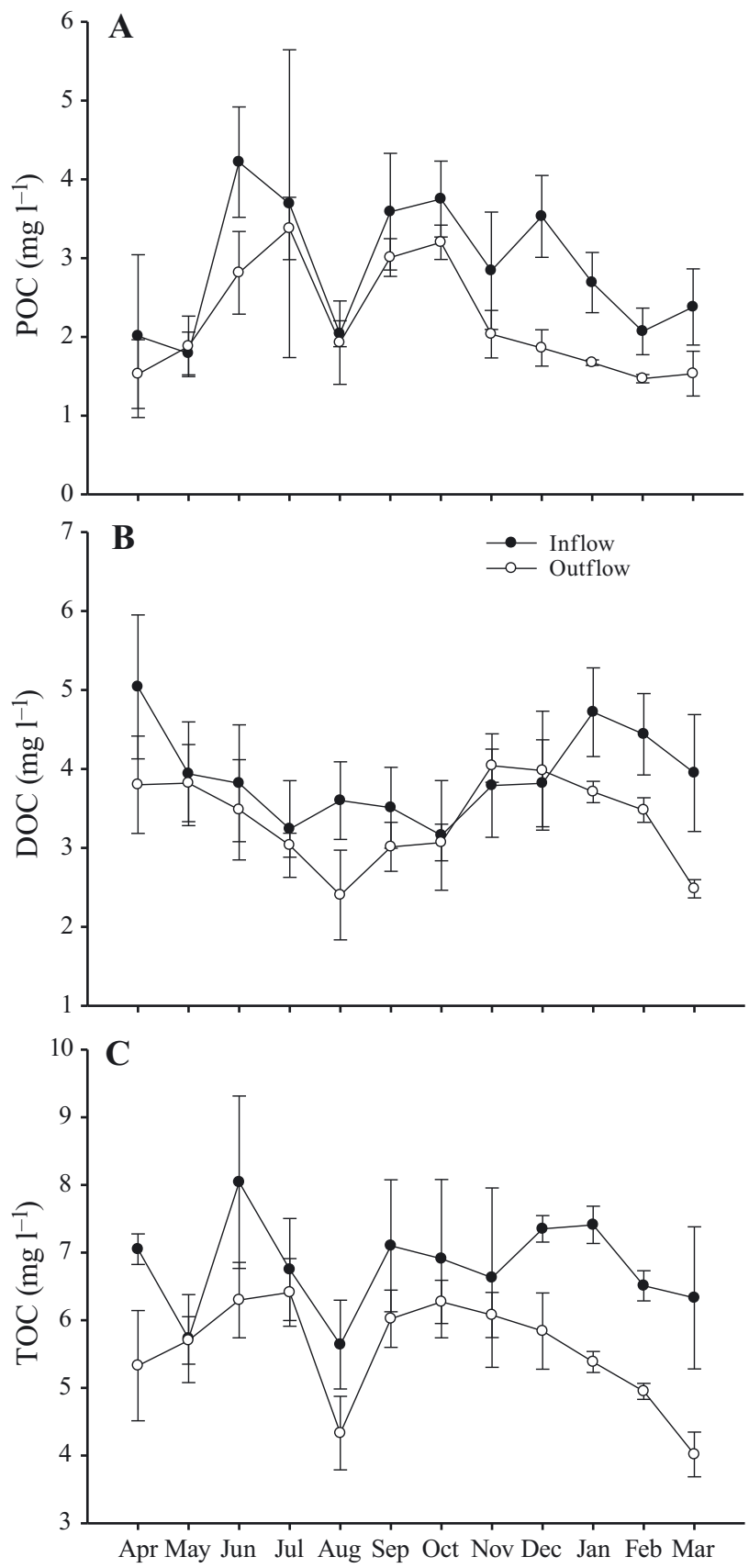

Fig. 1. Variations in (A) particulate organic carbon (POC), (B) dissolved organic carbon (DOC) and (C) total organic carbon (TOC) of inflow and outflow water from polyculture seawater ponds without feeding. Data are means \pm SD

to $5.04 \mathrm{mg} \mathrm{l}^{-1}$ and 5.73 to $8.04 \mathrm{mg} \mathrm{l}^{-1}$, respectively. POC, DOC and TOC outflows ranged from 1.53 to $3.38 \mathrm{mg} \mathrm{l}^{-1}, 3.03$ to $3.82 \mathrm{mg} \mathrm{l}^{-1}$ and 5.33 to $6.41 \mathrm{mg}$ $\mathrm{I}^{-1}$, respectively (Fig. 1). During the autumn farming season, inflow POC, DOC and TOC ranged from 2.04 to $3.75 \mathrm{mg} \mathrm{l}^{-1}, 3.16$ to $3.79 \mathrm{mg} \mathrm{l}^{-1}$ and 5.64 to $7.10 \mathrm{mg} \mathrm{l}^{-1}$, respectively. The outflows ranged from
1.93 to $3.20 \mathrm{mg} \mathrm{l}^{-1}, 1.47$ to $1.86 \mathrm{mg} \mathrm{l}^{-1}$ and 2.40 to $4.04 \mathrm{mg} \mathrm{l}^{-1}$ for POC, DOC and TOC, respectively (Fig. 1). During the winter farming season, inflow POC, DOC and TOC ranged from 2.07 to $3.53 \mathrm{mg}$ $\mathrm{l}^{-1}, 3.82$ to $4.72 \mathrm{mg} \mathrm{l}^{-1}$ and 6.33 to $7.41 \mathrm{mg} \mathrm{l}^{-1}$, respectively, whereas the outflow from the PSPs ranged from 3.03 to $3.82 \mathrm{mg} \mathrm{l}^{-1}, 2.48$ to $3.98 \mathrm{mg} \mathrm{l}^{-1}$ and 4.01 to $5.84 \mathrm{mg} \mathrm{l}^{-1}$ for POC, DOC and TOC, respectively (Fig. 1). Over 1 full year, organic carbon content was lower in the PSP outflow water during most farming seasons (Fig. 1C).

\section{Inflow and outflow TOC}

During the spring farming season, the TOC concentration of inflow water was significantly higher in the PSPs than that of the outflow water (991.4 \pm $27.7 \mathrm{~kg} \mathrm{ha}^{-1}$ versus $790.1 \pm 28.2 \mathrm{~kg} \mathrm{ha}^{-1} ; \mathrm{p}<0.05$ ). During the autumn farming season, TOC was also significantly higher in the inflow $(522.8 \pm 24.2 \mathrm{~kg}$ $\left.\mathrm{ha}^{-1}\right)$ than the outflow water $\left(454.9 \pm 30.6 \mathrm{~kg} \mathrm{ha}^{-1} ; \mathrm{p}<\right.$ $0.05)$. Additionally, TOC showed the same trend $(\mathrm{p}<$ $0.05 ; 164.0 \pm 2.54 \mathrm{~kg} \mathrm{ha}^{-1}$ in the inflow versus $73.7 \pm$ $1.39 \mathrm{~kg} \mathrm{ha}^{-1}$ in the outflow) during the winter farming season. During the 1-yr monitoring period, the outflow TOC accounted for $78.6 \%$ of the inflow TOC in PSPs.

\section{TOC fixed by primary production}

During the spring farming season, the NPP ranged from -0.12 to $1.59 \mathrm{~g} \mathrm{C} \mathrm{m}^{-2} \mathrm{~d}^{-1}$, increasing gradually with time, while the amount of TOC fixed by NPP was (mean $\pm \mathrm{SD}$ ) $635.2 \pm 88.4 \mathrm{~kg} \mathrm{ha}^{-1}$ (Table 2). During the autumn farming season, NPP ranged from $0.24 \mathrm{~g} \mathrm{C} \mathrm{m}^{-2} \mathrm{~d}^{-1}$ (November) to $2.51 \mathrm{~g} \mathrm{C} \mathrm{m}^{-2} \mathrm{~d}^{-1}$ (September), and TOC fixed by NPP was $1611.7 \pm$ $159.1 \mathrm{~kg} \mathrm{ha}^{-1}$. In contrast, NPP was mostly negative during the winter farming season $(-0.29$ to $0.07 \mathrm{~g} \mathrm{C}$ $\mathrm{m}^{-2} \mathrm{~d}^{-1}$ ). The consumed organic carbon was $115.1 \pm$ $142.4 \mathrm{~kg} \mathrm{ha}^{-1}$ during this season (Table 2).

\section{Sedimentary organic carbon content}

Organic carbon in PSP sediments accumulated throughout each farming season (Fig. 2), ranging from 2.61 to $3.40 \mathrm{mg} \mathrm{g}^{-1}$ in the spring farming season, from 4.50 to $6.13 \mathrm{mg} \mathrm{g}^{-1}$ in the autumn farming season, and from 5.07 to $6.66 \mathrm{mg} \mathrm{g}^{-1}$ during the winter farming season (Fig. 2). 
Table 2. Monthly variations of primary production (mean \pm $\mathrm{SD}, \mathrm{n}=3$ ) and the fixed total organic carbon (TOC) by primary production in polyculture seawater ponds (PSPs) without feeding. Carbon fixed by net primary production was evaluated as the difference between the carbon fixed by gross primary production and the carbon consumption by respiration

\begin{tabular}{|lcc|}
\hline & $\begin{array}{c}\text { Primary production } \\
\left(\mathrm{g} \mathrm{C}^{-2} \mathrm{~d}^{-1}\right)\end{array}$ & $\begin{array}{c}\text { Fixed TOC } \\
\left(\mathrm{kg} \mathrm{ha}^{-1}\right)\end{array}$ \\
\hline Apr & $-0.12 \pm 0.13$ & $-36.7 \pm 40.4$ \\
May & $0.28 \pm 0.18$ & $87.2 \pm 54.5$ \\
Jun & $0.36 \pm 0.30$ & $108.1 \pm 91.0$ \\
Jul & $1.59 \pm 0.30$ & $476.7 \pm 90.2$ \\
Total & - & $635.2 \pm 88.4$ \\
Aug & $1.71 \pm 0.37$ & $529.2 \pm 114.4$ \\
Sep & $2.51 \pm 0.10$ & $754.1 \pm 31.0$ \\
Oct & $0.83 \pm 0.43$ & $256.5 \pm 134.5$ \\
Nov & $0.24 \pm 0.14$ & $71.9 \pm 40.5$ \\
Total & - & $1611.7 \pm 159.1$ \\
Dec & $0.07 \pm 0.20$ & $21.7 \pm 61.1$ \\
Jan & $-0.29 \pm 0.16$ & $-91.3 \pm 48.4$ \\
Feb & $-0.20 \pm 0.15$ & $-57.2 \pm 41.7$ \\
Mar & $0.038 \pm 0.09$ & $11.7 \pm 27.1$ \\
Total & - & $-115.1 \pm 142.4$ \\
\hline
\end{tabular}

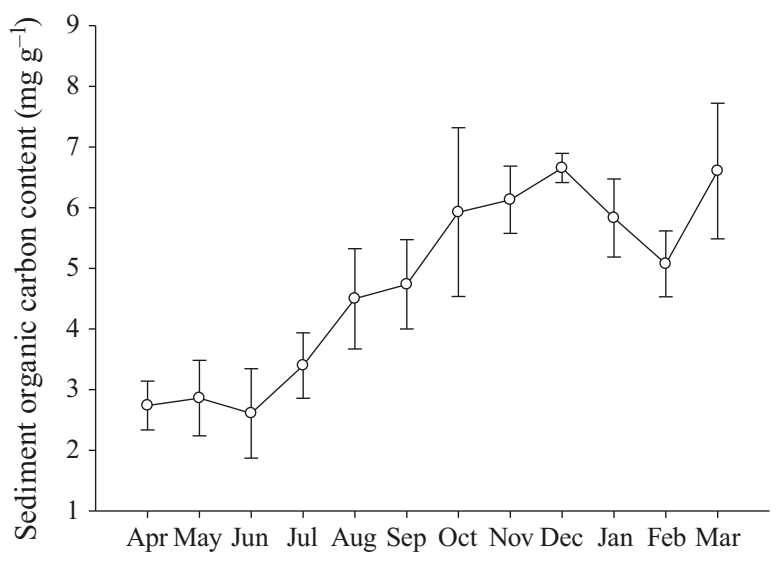

Fig. 2. Monthly variation in sediment organic carbon content of polyculture seawater ponds without feeding. Data are means $\pm \mathrm{SD}$

\section{Shrimp and sea cucumber organic carbon}

The organic carbon content in the dry matter of adult shrimp Marsupenaeus japonicus and sea cucumber Apostichopus japonicus was $42.16 \pm$ $2.09 \%$ and $27.4 \pm 1.0 \%$, respectively. In the PSPs, the TOC from harvested $M$. japonicus was $17.98 \pm 2.49$ $\mathrm{kg} \mathrm{ha}^{-1}\left(12.85 \pm 1.15 \mathrm{~kg} \mathrm{ha}^{-1}\right.$ in the spring farming season and $5.13 \pm 1.58 \mathrm{~kg} \mathrm{ha}^{-1}$ in the autumn farming season) (Table 3). Over $1 \mathrm{yr}, 24.96 \pm 3.15 \mathrm{~kg} \mathrm{ha}^{-1}$ of organic carbon resulted from $A$. japonicus.

\section{Organic carbon budget in PSPs}

The total TOC input to PSPs was (mean \pm SD) $3810.0 \pm 226.9 \mathrm{~kg} \mathrm{ha}^{-1}$ (Table 3). The organic carbon from the fixation of primary production accounted for $2131.7 \pm 266.3 \mathrm{~kg} \mathrm{ha}^{-1}$, which was $56.0 \%$ of all input. The organic carbon from inflow water was $1678.2 \pm$ $49.0 \mathrm{~kg} \mathrm{ha}^{-1}$ ( $44.0 \%$ of all input). The TOC output was $2251.9 \pm 546.7 \mathrm{~kg} \mathrm{ha}^{-1}$, of which outflow water accounted for $58.6 \%\left(1318.8 \pm 55.4 \mathrm{~kg} \mathrm{ha}^{-1}\right)$. The organic carbon output from the mass gained by the aquatic animals (shrimp and sea cucumbers) over 1 yr was relatively minor $\left(42.94 \pm 1.54 \mathrm{~kg} \mathrm{ha}^{-1} ; 1.9 \%\right.$ of all output). However, organic carbon output removed by macroalgae accounted for $\sim 39.5 \%$ of the total $\left(890.1 \pm 491.1 \mathrm{~kg} \mathrm{ha}^{-1}\right)$. The total accumulated organic carbon during the study interval was $1558.1 \pm$ $770.1 \mathrm{~kg} \mathrm{ha}^{-1}$ (Table 3).

\section{Gaseous carbon in PSPs}

The monthly cumulative carbon flux consisted of $\mathrm{CH}_{4}\left(\mathrm{CH}_{4}-\mathrm{C}\right)$ and $\mathrm{CO}_{2}\left(\mathrm{CO}_{2}-\mathrm{C}\right)$ in PSPs (Fig. 3). During the spring farming season, the $\mathrm{CO}_{2}-\mathrm{C}$ and $\mathrm{CH}_{4}-\mathrm{C}$ fluxes were $($ mean $\pm \mathrm{SD}) 166.2 \pm 39.1 \mathrm{~kg} \mathrm{ha}^{-1}$ and

Table 3. Inputs and outputs of organic carbon (mean $\pm \mathrm{SD}, \mathrm{n}=3$ ) in polyculture seawater ponds without feeding during different farming seasons and the annual carbon burial

\begin{tabular}{|c|c|c|c|c|c|}
\hline & ${ }_{-}$Input $(\mathrm{kg}$ & $\left.a^{-1}\right)$ & 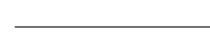 & Output (kg C ha-1) & \\
\hline & Primary production & Water inflow & Water outflow & Animals & Enteromorpha sp. \\
\hline Spring & $635.2 \pm 88.4$ & $991.4 \pm 27.7$ & $790.1 \pm 28.2$ & $12.85 \pm 1.15$ & $255.7 \pm 128.9$ \\
\hline Autumn & $1611.7 \pm 159.1$ & $522.8 \pm 24.2$ & $454.9 \pm 30.6$ & $5.13 \pm 1.58$ & $634.5 \pm 363.1$ \\
\hline Winter & $-115.1 \pm 142.4$ & $164.0 \pm 2.54$ & $73.7 \pm 1.39$ & - & - \\
\hline Annual & $2131.7 \pm 266.3$ & $1678.2 \pm 49.0$ & $1318.8 \pm 55.4$ & $42.94 \pm 1.54$ & $890.1 \pm 491.1$ \\
\hline $\begin{array}{l}\text { Carbon } \\
\text { Carbon }\end{array}$ & $\begin{array}{l}\text { get } \\
\mathrm{al}^{\mathrm{a}}\end{array}$ & & & $\begin{array}{c}1558.1 \pm 770.1 \\
77.9-155.8\end{array}$ & \\
\hline
\end{tabular}



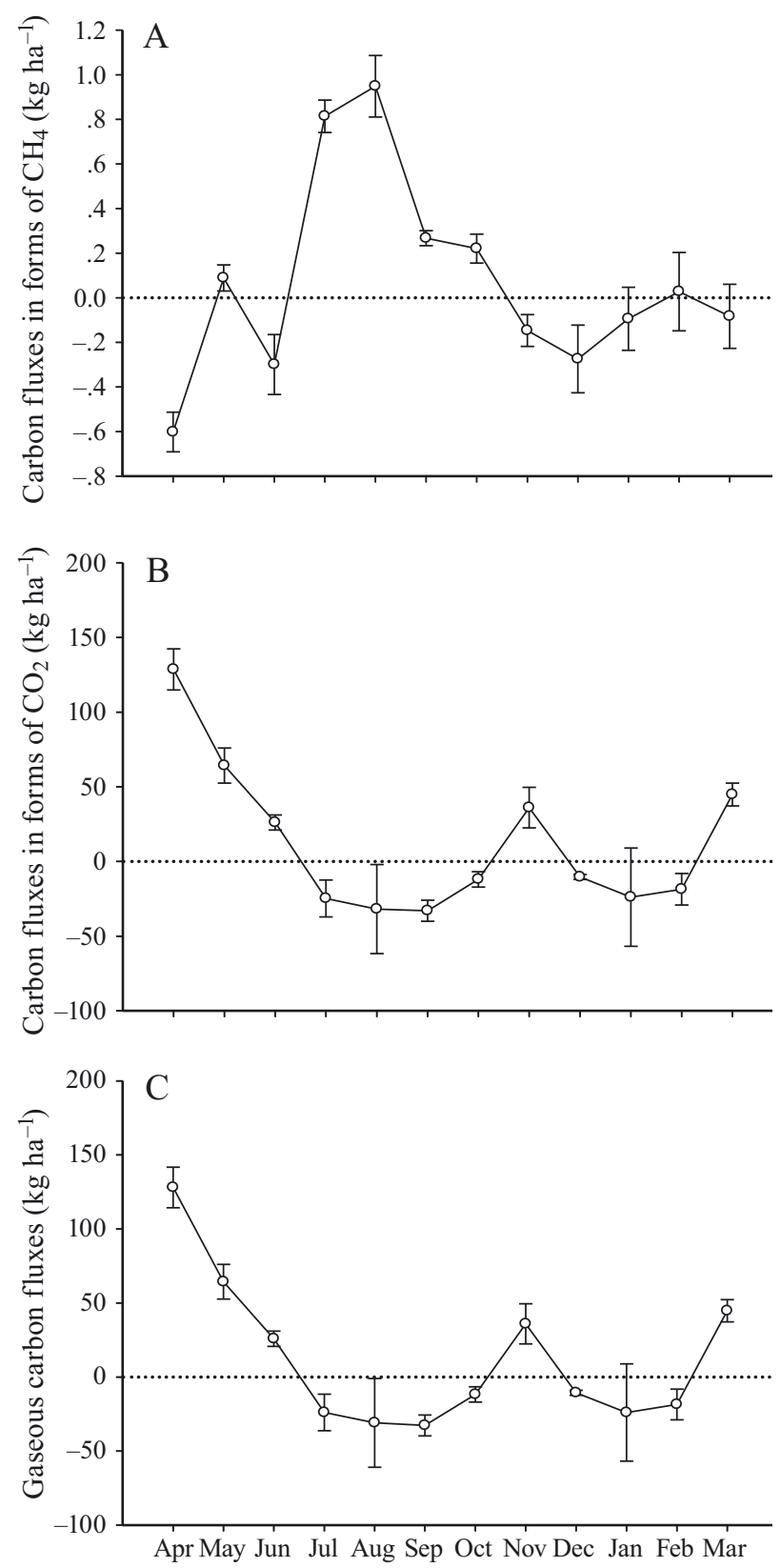

Fig. 3. Monthly cumulative carbon fluxes in the form of (A) $\mathrm{CH}_{4}\left(\mathrm{CH}_{4}-\mathrm{C}\right)$, (B) $\mathrm{CO}_{2}\left(\mathrm{CO}_{2}-\mathrm{C}\right)$ and $(\mathrm{C})$ gaseous carbon in polyculture seawater ponds (PSPs) without feeding. Data are means $\pm \mathrm{SD}$

$-0.21 \pm 0.26 \mathrm{~kg} \mathrm{ha}^{-1}$, respectively. The absorption of $\mathrm{CO}_{2}-\mathrm{C}$ was $-40.5 \pm 38.0 \mathrm{~kg} \mathrm{ha}^{-1}$, and the $\mathrm{CH}_{4}-\mathrm{C}$ flux across the water-air interface was $1.27 \pm 0.18 \mathrm{~kg} \mathrm{ha}^{-1}$ during the autumn farming season. During the winter, the $\mathrm{CO}_{2}-\mathrm{C}$ and $\mathrm{CH}_{4}-\mathrm{C}$ fluxes were $-10.6 \pm$ $19.9 \mathrm{~kg} \mathrm{ha}^{-1}$ and $-0.49 \pm 0.45 \mathrm{~kg} \mathrm{ha}^{-1}$, respectively. Over the study interval, the overall $\mathrm{CO}_{2}-\mathrm{C}$ and $\mathrm{CH}_{4}-$ C fluxes across the water-air interface were $112.3 \pm$ $86.0 \mathrm{~kg} \mathrm{ha}^{-1}$ and $0.68 \pm 0.90 \mathrm{~kg} \mathrm{ha}^{-1}$, respectively.

\section{DISCUSSION}

Previous studies on aquaculture ponds showed contrasting results: DOC, POC and TOC in outflow water were higher than in inflow water in shrimp ponds with a food supply (Biao et al. 2009), but lower than in inflow water in integrated sea cucumber ponds without feeding ( $\mathrm{Li}$ et al. 2015). The higher organic carbon content in the outflow originated from the food supply and thus led to carbon accumulation on the pond bottom, as well as increased waste discharge to coastal waters (Liu et al. 2002, Sahu et al. 2015). Our results showed that outflow TOC in PSPs was lower than inflow TOC across the study period (e.g. outflow TOC accounted for $78.6 \%$ of the inflow TOC). The utilization of food resources and aquatic production can be improved by integrating sea cucumbers with other aquatic animals; this alleviates the negative influences of farming activity on the environment (Qin et al. 2009, Ren et al. 2010, 2012). Therefore, PSPs systems that do not involve feeding could act as organic matter purification systems in coastal environments.

Feed used in aquaculture ponds contains inorganic nutrients that stimulate organic carbon production by phytoplankton (e.g. photosynthesis) (Boyd \& Tucker, 1998). Organic matter from dead plankton, unconsumed feed and excrement settles on the pond bottom and results in an increase in sedimentary organic carbon. For example, sedimentary organic carbon content reached $18.13 \mathrm{mg} \mathrm{g}^{-1}$ in shrimp Fenneropenaeus chinensis ponds and $16.6 \mathrm{mg} \mathrm{g}^{-1}$ in grass carp Ctenopharyngodon idellus ponds (Su et al. 2009, Xiong et al. 2016). The sedimentary organic carbon content in our studied PSPs ranged from 2.61 to $6.66 \mathrm{mg} \mathrm{g}^{-1}$ (Fig. 2), which is consistent with previous studies investigating sea cucumber culture systems without feeding (2.5 to $13.3 \mathrm{mg} \mathrm{g}^{-1}$ ) (Ren et al. 2012, Li et al. 2015), and lower compared with ponds with a feed supply. The sea cucumber is a deposit feeder, ingesting organic matter from the sediment; thus, its cultivation could reduce the accumulation of sedimentary organic matter in aquaculture ponds.

The $\mathrm{CH}_{4}$-C flux of the PSPs $\left(0.68 \mathrm{~kg} \mathrm{ha}^{-1}\right)$ was lower compared with that in Marsupenaeus japonicus culture ponds $\left(5.7 \mathrm{~kg} \mathrm{ha}^{-1}\right.$ ) (Chen et al. 2016). Nutrient loading and phytoplankton biomass increases with continuous feed supply and contributes to the larger $\mathrm{CH}_{4}$ emissions in $M$. japonicus ponds (Chen et al. 2016). The $\mathrm{CO}_{2}$-C flux of our PSPs $\left(112.3 \mathrm{~kg} \mathrm{ha}^{-1}\right)$, which represents $99.4 \%$ of the gaseous carbon flux, was lower than that of freshwater aquaculture ponds (1172.7 $\left.\mathrm{kg} \mathrm{ha}^{-1}\right)$ in a tem- 
perate monsoonal climate region (Chen et al. 2015). However, our $\mathrm{CO}_{2}$-C flux was higher than that of $M$. japonicus culture ponds $\left(-56.9 \mathrm{~kg} \mathrm{ha}^{-1}\right)$ (Chen et al. 2016). Organic carbon loading and primary production dominated the $\mathrm{CO}_{2}$ fluxes in these aquaculture ponds (Chen et al. 2015, 2016).

Previous carbon sequestration studies in aquaculture sediments showed that aquaculture ponds could be a carbon sink when $\mathrm{CO}_{2}$ and $\mathrm{CH}_{4}$ are not taken into account (Boyd et al. 2010, Adhikari et al. 2012). Carbon function studies using gas exchange and carbon burial balances showed that the ratio of gaseous carbon exchange across the water-air interface of various lakes was greater than 1, indicating that most lakes are a carbon source, except eutrophic Lake Donghu (Table 4). In our study, the net organic carbon budget was $1558.1 \mathrm{~kg} \mathrm{ha}^{-1}$ (Table 3). According to Boyd et al. (2010), the lowest carbon burial in aquaculture ponds is based on $95 \%$ of the difference between input and output eventually decomposing, whereas the largest burial value assumes that $90 \%$ is eventually decomposed. The carbon burial during our study period of the PSPs was $77.9-155.8 \mathrm{~kg} \mathrm{ha}^{-1}$ (Table 3). Thus, PSPs acted as a gaseous carbon source across the water-air interface. The ratios of carbon flux into the atmosphere to sedimentary carbon burial ranged from 0.73 to 1.45 (Table 4). Therefore, carbon retained by the sediment in PSPs could offset its release into the atmosphere. The model of gas exchange and carbon burial balance we developed from Lake Donghu showed that relatively high carbon sink values are because of high primary production, substantial allochthonous carbon input and intensive anthropogenic activity (Yang et al. 2008). The PSP primary production was generally lower $\left(-0.29-0.83 \mathrm{~g} \mathrm{C} \mathrm{m}^{-2}\right.$ $\mathrm{d}^{-1}$ ), except when the algal genus Enteromorpha grew from July to September. Constant water exchange might release organic carbon loading to PSPs, and the removal of Enteromorpha could also affect the PSP organic carbon budget.

Our results showed that PSPs eliminated inflow organic carbon and reduced sedimentary organic carbon accumulation. In addition, the carbon retained in PSP sediments can offset its carbon emissions to the atmosphere effectively.

Acknowledgements. This work was financially supported by the Primary Research and Development program of Shandong Province (no. 2016CYJS04A01) and funds from National Laboratory for Marine Science and Technology, Qingdao.
Table 4. Comparison of the ratios of gaseous carbon exchange to caron burial in different waters. PSPs: polyculture seawater ponds without feeding

\begin{tabular}{lccc|} 
& \multicolumn{1}{c}{ Type } & Ratio & Source \\
\hline PSPs & Without feed supply & $0.73-1.45$ & Present study \\
Donghu Lake & Eutrophic & 0.08 & Yang et al. (2008) \\
Dickie Lake & Oligotrophic & 1.16 & Dillon \& Molot (1997) \\
Crosson Lake & Mesotrophic & 3.43 & Dillon \& Molot (1997) \\
Plastic Lake & Oligotrophic & 3.88 & Dillon \& Molot (1997) \\
Global lakes & - & 2.3 & Cole et al. (1994) \\
& & & \\
\hline
\end{tabular}

\section{LITERATURE CITED}

Adhikari S, Lal R, Sahu BC (2012) Carbon sequestration in the bottom sediments of aquaculture ponds of Orissa, India. Ecol Eng 47:198-202

Archer DE, Eshel G, Winguth A, Broecker W, Pierrehumbert $\mathrm{R}$, Tobis M, Jacob R (2000) Atmospheric $\mathrm{pCO}_{2}$ sensitivity to the biological pump in the ocean. Global Biogeochem Cycles 14:1219-1230

Biao X, Tingyou L, Xipei W, Qi Y (2009) Variation in the water quality of organic and conventional shrimp ponds in a coastal environment from Eastern China. Bulg J Agric Sci 15:47-59

Boyd CE, Tucker CS (1998) Pond aquaculture water quality management. Kluwer, Boston, MA

* Boyd CE, Wood C, Chaney PL, Queiroz JF (2010) Role of aquaculture pond sediments in sequestration of annual global carbon emissions. Environ Pollut 158:2537-2540

Chen Y, Dong SL, Wang ZN, Wang F, Gao QF, Tian XL, Xiong YH (2015) Variations in $\mathrm{CO}_{2}$ fluxes from grass carp (Ctenopharyngodonidella) polyculture ponds. Aquacult Environ Interact 8:31-40

Chen Y, Dong SL, Wang F, Gao QF, Tian XL (2016) Carbon dioxide and methane fluxes from feeding and no-feeding mariculture ponds. Environ Pollut 212:489-497

* Cole JJ, Caraco NF, Kling GW, Kratz TK (1994) Carbon dioxide supersaturation in the surface waters of lakes. Science 265:1568-1570

* Dillon PJ, Molot LA (1997) Dissolved organic and inorganic carbon mass balances in central Ontario lakes. Biogeochemistry 36:29-42

Downing JP, Meybeck M, Orr JC, Twilley R, Scharpenseel H (1993) Land and water interface zones. Terrestrial biospheric carbon fluxes quantification of sinks and sources of $\mathrm{CO}_{2}$. Springer, Dordrecht

Eaton AD, Clesceri LS, Greenburg A (1995) Standard methods for the examination of water and wastewater. American Public Health Association, United Book Press, Baltimore, MD

Franzén LG, Lindberg F, Viklander V, Walther A (2012) The potential peatland extent and carbon sink in Sweden, as related to the peat land / ice age hypothesis. Mires Peat 10:1-19

Grasshoff K, Kremling K, Ehrhardt M (2007) Methods of seawater analysis, 3rd edn. Wiley-VCH, Weinheim

Guo K, Zhao W, Jiang ZQ, Dong SL (2017) A study of organic carbon, nitrogen and phosphorus budget in jellyfishshellfish-fish-prawn polyculture ponds. Aquacult Res 48: 68-76

Holmer M, Marba N, Diaz E (2007) Sedimentation of organic 
matter from fish farms in oligotrophic Mediterranean assessed through bulk and stable isotope $\left(\delta^{13} \mathrm{C}\right.$ and $\left.\delta^{15} \mathrm{~N}\right)$ analyses. Aquaculture 262:268-280

Hopkins JS, Ii RDH, Sandier PA, Browdy CL, Stokes AD (1993) Effect of water exchange rate on production, water quality, effluent characteristics and nitrogen budgets of intensive shrimp ponds. J World Aquacult Soc 24: 304-320

Li JW, Dong SL, Gao QF, Wang F, Tian XL, Zhang SS (2015) Total organic carbon budget of integrated aquaculture system of sea cucumber Apostichopus japonicus, jellyfish Rhopilemaesculenta and shrimp Fenneropenaeus chinensis. Aquacult Res 45:1825-1831

Liu GC, Li DS, Dong SL (2002) Organic carbon balance in prawn cultivating ponds. Acta Oceanol Sin 24:84-91 (in Chinese)

Murphy J, Riley JP (1962) A modified single solution method for the determination of phosphate in natural waters. Anal Chim Acta 27:31-36

National Standardization Management Council (2007) Specifications for oceanographic survey, Part 6. Marine biological survey 6:6-7. GB/T 12763.6.

Ortiz-Llorente MJ, Alvarez-Cobelas M (2012) Comparison of biogenic methane emissions from unmanaged estuaries, lakes, oceans, rivers and wetlands. Atmos Environ 59:328-337

* Qin CX, Dong SL, Tan FY, Tian XL, Wang F, Dong YW, Gao QF (2009) Optimization of stocking density for the sea cucumber, Apostichopus japonicas selenka, underfeedsupplement and non-feed-supplement regimes in pond culture. J Ocean Univ China 8:296-302

Ren YC, Dong SL, Wang F, Gao QF, Tian XL, Liu F (2010) Sedimentation and sediment characteristics in sea cucumber Apostichopus japonicus (Selenka) culture ponds. Aquacult Res 42:14-21

Ren YC, Dong SL, Qin CX, Wang F, Tian XL, Gao QF (2012) Ecological effects of co-culturing sea cucumber Apostichopus japonicus (Selenka) with scallop Chlamys farreri in earthen ponds. . Chin J Oceanology Limnol 30:71-79

Rödenbeck C, Keeling R, Bakker D, Metzl N, Olsen A,

Editorial responsibility: Alejandro Buschmann,

Puerto Montt, Chile
Sabine C, Heimann M (2013) Global surface-ocean $\mathrm{pCO}_{2}$ and sea-air $\mathrm{CO}_{2}$ flux variability from an observationdriven ocean mixed-layer scheme. Ocean Sci 9:193-216

Sahu BC, Adhikari S, Mahapatra AS, Dey L (2015) Nitrogen, phosphorus, and carbon budgets in polyculture ponds of Indian major carps and giant freshwater prawn in Orissa State, India. J Appl Aquacult 27:365-376

Su YP, Ma S, Tian XL, Dong SL (2009) An experimental study on nitrogen, phosphorus and carbon budgets in intensive pond of shrimp Fenneropenaeus chinensis. South China Fish Sci 5:54-58 (in Chinese with English Abstract)

Thomas MLH (1988) Photosynthesis and respiration of aquatic macro-flora using the light and dark bottle oxygen method and dissolved oxygen analyzer. In: Lobban CS, Chapman DJ, Kremer BP (eds) Experimental phycology: a laboratory manual. Cambridge University Press, Cambridge

* Xing YP, Xie P, Yang H, Ni L, Wang Y, Rong K (2005) Methane and carbon dioxide fluxes from a shallow hypereutrophic subtropical Lake in China. Atmos Environ 39:5532-5540

Xiong YH, Wang F, Chen Y, Liu F (2016) Study on distribution of different carbon forms in overlying and sediment interstitial waters in different grass carp polyculture models. Period Ocean Univ China 46:22-30 (in Chinese with English Abstract)

Yang H, Xing YP, Xie P, Ni L, Rong K (2008) Carbon source/sink function of a subtropical, eutrophic lake determined from an overall mass balance and a gas exchange and carbon burial balance. Environ Pollut 151: $559-568$

* Zhang GL, Zhang J, Liu SM, Ren JL, Xu J, Zhang F (2008) Methane in the Changjiang (Yangtze River) Estuary and its adjacent marine area: riverine input, sediment release and atmospheric fluxes. Biogeochemistry 91:71-84

Zhao W, Dong SL, Li DS, Zhang ZQ, Shentu QC (2002) The primary productivity of phytoplankton in saline-alkaline ponds. Acta Hydrobiol Sin 27:47-54 (in Chinese with English Abstract)

Submitted: April 12, 2017; Accepted: August 6, 2018 Proofs received from author(s): October 10, 2018 